Research Article

\title{
Lessons Learned: The Multifaceted Field of (Digital) Neighborhood Development
}

Madeleine Renyi, Care \& Technology Lab (IMTT), Furtwangen University, Furtwangen, Germany; Institute for Information Management and Information Systems Engineering (IMU), Department of Accounting and Information Systems, University of Osnabrück, Osnabrück, Germany,info@madeleinerenyi.de

Anna Hegedüs, Careum School of Health, Zürich, Switzerland, anna.hegedues@bfh.ch

Paul Schmitter, Institute of Facility Management, Life Sciences and Facility Management, ZHAW Zurich University of Applied Sciences, Wädenswil, Switzerland, paul.schmitter@zhaw.ch

Fabian Berger, Careum School of Health, Zürich, Switzerland, fabian.berger@careumhochschule.ch

Thomas M. Ballmer, Institute of Occupational Therapy, School of Health Professions, ZHAW Zurich University of Applied Sciences, Winterthur, Switzerland, thomasmichael.ballmer@zhaw.ch

Edith Maier, Fachhochschule Ostschweiz, St. Gallen, Switzerland, edith.maier@ost.ch Christophe Kunze, Care \& Technology Lab (IMTT), Furtwangen University, Furtwangen, Germany, christophe.kunze@hs-furtwangen.de 


\title{
Lessons Learned: The Multifaceted Field of (Digital) Neighborhood Development
}

\begin{abstract}
In a cross-national project, 14 neighborhoods from Germany, Austria and Switzerland were accompanied on their way to digitally supported neighborhood work. This paper discusses general requirements, choosing a suitable digital tool, the implementation process as well as the challenges faced by the various stakeholders. The following factors have been found to play a major role in sustainable neighborhood work: good fit with overall development strategy, interplay between online neighborhood work and physical interactions, strong existing neighborhood management structures, strategic planning of digitalization activities, start-up funding for innovation activities, and above all, the presence of a committed person or team as well as interesting content to attract users. Depending on the neighborhood, self-managed and individualistic solutions are preferred to generic and/or commercial solutions. There is no 'fit-forall' path to sustainable digitally supported neighborhoods.
\end{abstract}

Keywords: neighborhood development; technology implementation; lessons learned

\section{Introduction}

Neighborhood Development and the Value of Information and Communication Technologies (ICT)

As people age in their social environment (e.g., neighborhood, district, or village), their radius of movement decreases. However, the everyday need to maintain social contacts and interact with other people remains (Meyer, 2016). The social environment of the neighborhood thus becomes all the more important (Steffen \& Otto, 2017).

Neighborhood development concepts have established themselves in recent years as a central element of coping with demographic challenges (see WHO, 2007; Deutscher Bundestag, 2016; Bäuerle \& Scherzer, 2009; Michell-Auli \& Kremer-Preiß, 2013). These concepts strengthen smallscale social-spatial structures and mutual aid (ibid.). They are based on specific local conditions and resources (ibid.). Participatory development and civic mobilization towards a social neighborhood in housing, social services, assistance, and care are aimed for (ibid.).

In Germany, Austria, and Switzerland, there is currently a strong, but varying emphasis on neighborhood approaches that lacks a practical, cross-national transfer of experiences. While (in Germany) there is a diverse and constantly changing range of neighborhood-related digital platforms and social media (Schreiber \& Göppert, 2018), the connections between neighborhood development and the implementation and use of digital neighborhood platforms and other 
digital tools for neighborhood social networking are still insufficiently researched (Vogel et al., 2020). There is considerable potential for mutual benefit: Ageing-appropriate information and communication systems can activate and promote neighborhood social interaction, support and stimulate civic engagement and neighborhood assistance, stabilize care at home, and simplify and encourage citizen participation processes. ICT thus offers neighborhood projects considerable underutilized opportunities to achieve the goals of neighborhood development more efficiently. Ultimately, this is a matter of public health and health promotion, since social interaction and loneliness are central factors in health outcomes (Klie, 2016).

\section{Guidelines to Support Neighborhood Development}

Vogel et al. (2020) developed a taxonomy of online neighborhood social networks (ONSN) and conclude that these networks are "socio-technical artifacts" where successful implementation in a neighborhood does not only depend on their technical functionality, but also on how they are embedded into the sociocultural context: "While the design of an ONSN may be technically sound, it is equally important to consider factors such as local facilitation, integration of organizations and institutions as well as the delimitation of neighborhoods..." In a related implementation study, Vogel et al. (2019) report reluctance among older users to request support over the platform, marked differences in technology use proficiency among users that indicate a need for technical support, and privacy and security concerns (Vogel et al., 2019). Privacy concerns among potential users of digital neighborhood networks are also described by Masden et al. in their 2014 study of the commercial platform nextdoor. Schelisch and Walter (2021) conducted interviews with 12 representatives of digital neighborhood projects in Germany. They, too, conclude that users' digital skills, concerns about data privacy, and existing neighborhood structures must be considered. Like Schreiber and Göppert (2018), they state the need for a person to be in charge of managing and coordinating digital tools. Therefore, many barriers to ICT use could be overcome with corresponding offerings in neighborhoods. Experience indicates, for example, that municipal advisory centers for assistive technology can reduce information deficits regarding available technology, improve the availability of onsite technologysupported assistance systems and services, and thus promote a needs-based supply of technical support (Röll et al., 2016). These neighborhood offerings can therefore act as multipliers of technology use.

Renyi et al. (2020) developed a maturity model for information and communication technologysupported neighborhood development based on a Delphi study. They identify 12 dimensions important for a successful implementation of these tools. The dimensions included, among others, the degree to which social networks already exist offline, the degree of citizen empowerment and participation in neighborhood work, the inclusivity towards disadvantaged groups, and the availability of sufficient funding.

In summary, the implementation of neighborhood digital tools depends not only on the technical functionality of such tools, but also strongly on the characteristics of the neighborhood (e.g., social and technological infrastructure) and the potential users (e.g., differences in digital skills). 
General factors of technology acceptance processes, including "perceived usefulness" and "perceived ease of use" (Venkatesh \& Bala, 2008; Davis et al. 1989) are still crucial factors.

\section{Study Aim and Research Question}

This article presents a study that investigated how neighborhood development concepts and information systems can mutually benefit from an integrated approach. In a cross-national project, neighborhoods in the Lake Constance region were scientifically accompanied amidst their digitization projects. Since sustainable neighborhood development can only emerge in longterm processes, the study focused on neighborhoods that already had some exhibited structures of citizen mobilization. This ensured the integration of technology within a limited project duration. Actions and decisions within the neighborhoods were monitored and discussed by a cross-national scientific board. The measures initiated within the study enabled the participating neighborhoods to use technical solutions to support their work in the long term and to promote the demand-oriented use of ICT. This article summarizes recommendations for action that will hopefully enable a broad, cross-national transfer of experience. It therefore answers the following research question:

Which stakeholders' experiences with implementing digital neighborhood development tools are relevant across countries?

\section{Materials and Methods}

To answer the research question, the researchers conducted a qualitative content analysis (Kuckartz; 2014) based on primary and secondary data (Zeidler \& Braun, 2012) gathered during the support of the communities. The next section describes the study's background, the data collection, and the content analysis. The researchers had dual roles, acting both as neutral observers and as enablers supporting the projects with their knowledge.

\section{Study Background and Sampling}

This study was part of a project of the Internationale Bodensee Hochschule (IBH; engl. International Lake Constance University), Technik im Quartier (engl. Technology in the Neighborhood; duration: 2018 to 2021), focusing on its region. The Lake Constance region is a diverse region with a mixture of rural and urban regions.

The involved scientists were well connected and drew on contacts from previous projects for the study sampling. Based on this network, between 2018 and 2019, rural and urban neighborhoods in Germany, Austria, and Switzerland were contacted and invited to participate in this study. As an inclusion criterion, their neighborhood development structures had to be already established, since sustainable neighborhood development can only emerge in long-term processes. The governance of these development structures, however, could lie on informal ground as well as within a municipal department. A further criterion was that digital neighborhood technology was implemented or planned to be implemented in a timely manner. While the study sampling may be described as a convenience sample, the sampling was also drawn on theoretical considerations. Previous experiences show that neighborhood projects differ between urban and 
rural areas and are also strongly influenced by structural and cultural differences in the national welfare systems. The scientists made sure that this diversity was represented in the sample.

\section{Data Collection}

Each participating neighborhood was assigned a scientific collaborator to act as a direct contact for the study and to support and advise the neighborhood if needed. Each assigned researcher

- identified and characterized existing technology-supported approaches for assisting neighborhood activities and measures for providing technical support systems in the assigned neighborhoods;

- supported the assigned neighborhoods in selecting and prioritizing suitable approaches for the respective development concept through workshop discussions;

- supported the assigned neighborhoods in initiating and implementing the use of appropriate technology-related services;

- enabled mutual learning between neighborhood actors involved through cooperative exchange and learning settings to promote research-based iterative development processes; and

- continuously evaluated the implementation and derived transferable recommendations for action in the assigned neighborhoods.

While supporting the neighborhoods, the researchers collected meeting minutes and correspondence material (e-mails, recordings of telephone conversations) to document the development of the project - secondary data, and interviewed neighborhood actors regarding special topics - primary data. All data regarding information about the included neighborhoods and their digitization projects exchanged between March 2018 and June 2020 were eligible and included in the data pool. Based on this, the researchers carried out a content analysis. In total, more than 134 documents were gathered. The numbers of documents per neighborhood varied between two and 35, while most scientific collaborators gathered around 5-15 documents per neighborhood community. The variance in the numbers can be attributed to the fact that not every neighborhood community needed the same amount of counseling. Further details on the documents used are documented in the supplementary material.

\section{Content Analysis}

To reduce the risk of bias, since the researchers were personally involved in the neighborhood projects, an external research collaborator, listed as co-author of the paper, was consulted for the analysis process. The researchers followed the seven-step process of a content-structuring content analysis by Kuckartz (2014). Data analysis was carried out using the content analysis software MAXQDA.

In the first phase, the researchers carefully read transcribed texts and passages for analysis marking important areas. Special features and evaluation ideas were recorded in the form of memos. In the second phase, the researchers developed directly thematic main categories of the 
material, and they carried out a test run through a part of the data. In the third step, the researchers ran through the entire text corpus line by line and assigned relevant sections to the categories. Since text sections and even individual sentences can contain several topics, multiple coding of such sections or sentences was possible. The coding unit (i.e., the text segment assigned to a category) was chosen in such a way that the meaning is understandable even without context. Therefore, the researchers also coded questions or larger sections contributing to understanding.

In the fourth step, the researchers compiled all of the passages assigned to each of the main categories - neighborhoods, general condition, implementation, technology, stakeholders, participation, evaluation, COVID-19 pandemic, and outcomes. In the fifth step, the researchers inductively created subcategories. This meant performing a differentiation of the categories, which were initially relatively general. Similarities and differences in the text segments could then be easily identified. As the subcategories initially existed in an unordered list, the researchers subsequently ordered and systematized them, with emphasis on keeping it "as simple as possible, as differentiated as necessary" (Kuckartz 2016). For each of the subcategories created in the work, the researchers formulated a brief definition to simplify the differentiation from other categories. Each subcategory was provided with a meaningful citation, a so-called anchor example. The main category technology e.g., was divided into the sub-categories of user requirements, possible technologies, technology requirements, requirements for operators, and reasons for rejection.

In the sixth phase, the researchers again ran through the material with the differentiated category system. Ultimately, 2,354 text segments were found to be relevant. On this basis, the researchers carried out simple and complex analyses and visualizations in the seventh phase.

\section{Results}

This section presents only the highlights of the content-structuring content analysis and is therefore not structured according to the main categories. It is divided into sample description, implementation phase, and stakeholders and their roles. As an outcome we identified several contradictory facets, which are presented at the end.

\section{Sample Description}

\section{Demographics}

The study accompanied 14 neighborhoods: four German, two Austrian, and eight Swiss neighborhoods. Six were mostly rural in character, while eight were nearby or part of a larger city. The number of people living in the neighborhoods ranged from about 1,500 to 20,000. The majority of neighborhoods had less than 5,000 inhabitants. The neighborhoods varied in their age distribution, though older adults constituted a high proportion.

Most neighborhoods had shopping facilities of some kind. While urban neighborhoods had strong healthcare structures, in the rural neighborhoods, there was a lack of specialists, hospital connections, and inpatient care facilities. The reliability and regularity of public transportation 
tended to be poorer in rural neighborhoods than in urban ones. The social milieu of the neighborhoods ranged from poor to well-off and was primarily described as well-mixed. Although migration was rather low, some urban neighborhoods had a high proportion of foreigners. People lived in rented and owned properties alike, and a higher proportion tended to live alone in old age. Only a few neighborhoods claimed to have a large number of neighborhood meeting points. The construction of community centers was planned in some of the neighborhoods.

\section{Technology, Digitization, and Media Usage}

In rural areas, comprehensive network coverage was lacking, which limited access to and use of Internet services. In these cases, expanding broadband Internet was an urgent municipal goal. Information was available in the neighborhoods on various media channels. In most cases, classic websites were operated by neighborhood associations, the local authority, or businesses to communicate information to citizens. A municipal, active presence in social media channels such as Facebook or Twitter rarely existed. Some of the citizens were very active on these media platforms in different groups. An overview of the various communication options and social media groups was hard to achieve. A municipal print medium, as a bundled information channel, was operated only in some of the neighborhoods.

\section{Local and Regional Politics and Support within Society}

At the municipal level, there was a wealth of experience in neighborhood work. Most local municipalities promoted a structured approach based on guidelines and procedural models, for example, for strategy development. However, in most cases, there was little standardization in the neighborhoods. Networking between neighborhood actors and with supraregional actors was not very pronounced. However, where neighborhood associations existed, neighborhood work was usually carried out by citizens in a strong network, often beyond the boundaries of the neighborhood.

\section{Implementation Phase}

Before a tool to support neighborhood development is implemented, various activities take place. These include the establishment of an infrastructure, strategy development and goalsetting, the allocation of resources both human and financial, the capture and definition of user requirements, and the selection of a tool that fulfils these requirements. In the following section, these activities are discussed in more detail.

\section{Setting Up a Physical and Virtual Infrastructure}

The introduction of technology presupposes the existence of certain infrastructure, like meeting facilities with access to the Internet and appropriate hardware. If not available onsite, these had to be created. In most cases, publicly operated meeting places were already available in the form of neighborhood centers with cafeterias, counseling and training facilities, green spaces, or parks. Comparable facilities were sometimes offered and run by private businesses. In some neighborhoods, the creation of physical places that could be used for software training, for 
instance, was assigned top priority. The challenge consisted in finding synergies between physical and virtual spaces.

"The foundation for the digital neighborhood project was laid with a preliminary project in another neighborhood. This preparatory work was necessary for it to spread to other neighborhoods. A new group took the idea, and then technically improved it. Then came a third neighborhood. They saw

that people could be motivated for projects and also wanted to create something." (interview protocol, municipal coordinator, neighborhood 4+5+6, Switzerland, 2020)

However, the need for technical support was not recognized by all the stakeholders interested in neighborhood development. Whereas some regarded it as a means to solve individual problem situations (e.g., for organizing supporters in neighborhood assistance), others regarded it as a replacement for missing municipal print media. In some cases, the use of technology to promote the sustainable establishment of neighborhood services was only considered when real-world services were not available or could not be established sustainably. In general, it was found that if there was already a strong network operating at the neighborhood level, there was little need for change. As a result, the introduction of technology was not considered a priority.

Nevertheless, in some neighborhoods, citizens did see the need for action. Frequently, it was neighborhood associations that took the initiative and acted as the driving force. Even then, many felt that it was up to the municipality to take on the task of organizing and funding digital support for neighborhood development.

\section{Developing Strategies and Setting Goals}

Although the individual reasons for adopting technology differed, some overarching goals could be identified. There was a desire for the neighborhood platform to be used by a large proportion of citizens. Though the neighborhoods did not define any precise target numbers, success was measured by the extent to which user numbers increased. Sustainability was sought both in terms of technology (i.e., available round the clock with regular updates) and in terms of those responsible for keeping the platform maintained. In some neighborhoods, technology was expected to compensate for staff shortages and promote volunteer work.

The initiating phase tended to be characterized by a series of discussions with different stakeholders. In these, the stakeholders became familiar with each other, explored ideas, weighed advantages and disadvantages, and planned the launch and implementation of the tool or platform. Decisions were made about responsibilities and roles, contractual issues, scheduling of project measures, and priorities. This process was closely linked with developing and refining a strategy for the future, which was especially critical in neighborhoods that adopted a top-down approach. In such cases, there was a need to reach a common understanding with the key figures in the communities to formulate clear directions and objectives. Goal-setting was generally described as an important process that took time, especially given the diversity of the actors involved. If the changes were initiated bottom-up or triggered by grass-roots movements, shared 
ideas tended to create cohesion and a team spirit early on. Generally, a clear vision and strategy for digitally supported neighborhood work proved to be essential prerequisites for engaging further members from the communities.

\section{Allocating Resources and Financing}

An important aspect in the pre-launch phase concerned the acquisition and provision of resources and finances. In some neighborhoods, dedicated personnel were made available by the municipalities for the projects. Though the costs of the technology were covered by funding bodies like the IBH in some cases (Internationale Bodenseehochschule, 2020), funding was generally limited to periods of one to four years covering the start-up phase.

To ensure the sustainability of the projects beyond the funding period, raising further funds was necessary. In most cases, the aim was to have the municipalities cover or at least co-finance the operating costs. As far as personnel resources were concerned, the responsible persons' funding ceased in some cases after the start-up period, whereas in other communities, the responsible persons were firmly established as part of the municipal government (e.g., as neighborhood managers). Sometimes, citizens independently organized such positions, a precarious solution, especially if there is a lack of funds and few volunteers involved in the project. Volunteers also tend to drop out from time to time, leaving gaps difficult to fill. It proved therefore to be of utmost importance to build up a sustainable personnel structure.

\section{Defining Requirements for Digital Neighborhood Platforms}

Choosing an appropriate neighborhood platform proved to be challenging and time-consuming, much more so than choosing an application with a more limited functionality. For the selection process, it was not only important to define what functions were required, but also to examine who provided the solution and how and by whom it was operated and maintained. Thus, neighborhood platforms, when conceived as digital village squares bringing together various social actors with different expectations and objectives, come with a great variety of requirements. Table 1 provides an overview of both functional and nonfunctional requirements that were gathered through this study. 
Table 1: Requirements of digital neighborhood platforms

\begin{tabular}{|c|c|}
\hline $\begin{array}{l}\text { Functional } \\
\text { Requirements }\end{array}$ & Description \\
\hline Information Hub & $\begin{array}{l}\text { Overview of important neighborhood content } \\
\text { (only accessible via personal registered account) }\end{array}$ \\
\hline News & $\begin{array}{l}\text { Posts of news, current events, and important issues regarding the } \\
\text { neighborhood on notice board; townhall messages or "tweets" }\end{array}$ \\
\hline $\begin{array}{l}\text { Neighborhood } \\
\text { Directory }\end{array}$ & $\begin{array}{l}\text { Integration / presentation of associations, businesses, and other locally } \\
\text { important stakeholders }\end{array}$ \\
\hline $\begin{array}{l}\text { Group } \\
\text { Functionalities }\end{array}$ & $\begin{array}{l}\text { Functions for establishing groups, carrying out tasks, and presenting } \\
\text { developments on the platform }\end{array}$ \\
\hline Messaging & $\begin{array}{l}\text { Bilateral communication between community members; for certain cases, } \\
\text { push messages }\end{array}$ \\
\hline Calendar & Overview of events in the neighborhood and possibly beyond, if relevant \\
\hline $\begin{array}{l}\text { Digital } \\
\text { Marketplace }\end{array}$ & Pin board for private advertisements \\
\hline $\begin{array}{l}\text { Reservation } \\
\text { Facility }\end{array}$ & $\begin{array}{l}\text { Booking system for communal spaces / rooms available in the } \\
\text { neighborhood }\end{array}$ \\
\hline Surveys & Determination system for suitable dates, query issues of all kind \\
\hline Networking & Option for integrating additional neighborhoods or districts \\
\hline $\begin{array}{l}\text { Non-Functional } \\
\text { Requirements }\end{array}$ & Description \\
\hline Layout and Design & $\begin{array}{l}\text { Platform that is self-explanatory and easy to navigate with intuitive and } \\
\text { well-structured user interfaces (GUI) }\end{array}$ \\
\hline Accessibility & $\begin{array}{l}\text { Access via Internet browser and mobile devices (iOS, Android, and } \\
\text { Windows app; i.e., a cross-platform solution) and with consideration of } \\
\text { people with motor or (minor) cognitive impairments }\end{array}$ \\
\hline $\begin{array}{l}\text { Adaptability and } \\
\text { Extensibility }\end{array}$ & $\begin{array}{l}\text { Design that can be customized to accommodate neighborhood-specific } \\
\text { requirements }\end{array}$ \\
\hline $\begin{array}{l}\text { Automatic Login } \\
\text { and Single-Sign-On }\end{array}$ & $\begin{array}{l}\text { Option for restricting access of certain areas to registered users; public } \\
\text { content access for people outside the neighborhood such as relatives, } \\
\text { students, commuters, etc. }\end{array}$ \\
\hline $\begin{array}{l}\text { Data Protection } \\
\text { and Privacy }\end{array}$ & Access only via personal registered account; data regulation conformity \\
\hline
\end{tabular}

\section{Selecting an Appropriate Platform}

There was a general consensus that the platform should act as an information and exchange hub that promotes social networking in the neighborhood and possibly beyond. The platform was also expected to provide the infrastructure for local groups to organize themselves in an easy and accessible manner, whilst at the same time guaranteeing data security and protection. 
Regular user feedback was seen as essential for adapting the applications to potentially changing user needs.

With these requirements in mind, the project team examined the platforms already in use in some neighborhoods and platforms that might be recommended to new neighborhood initiatives. Four platforms were identified that fulfilled at least most of the requirements of the participating neighborhoods (see Figure 1).

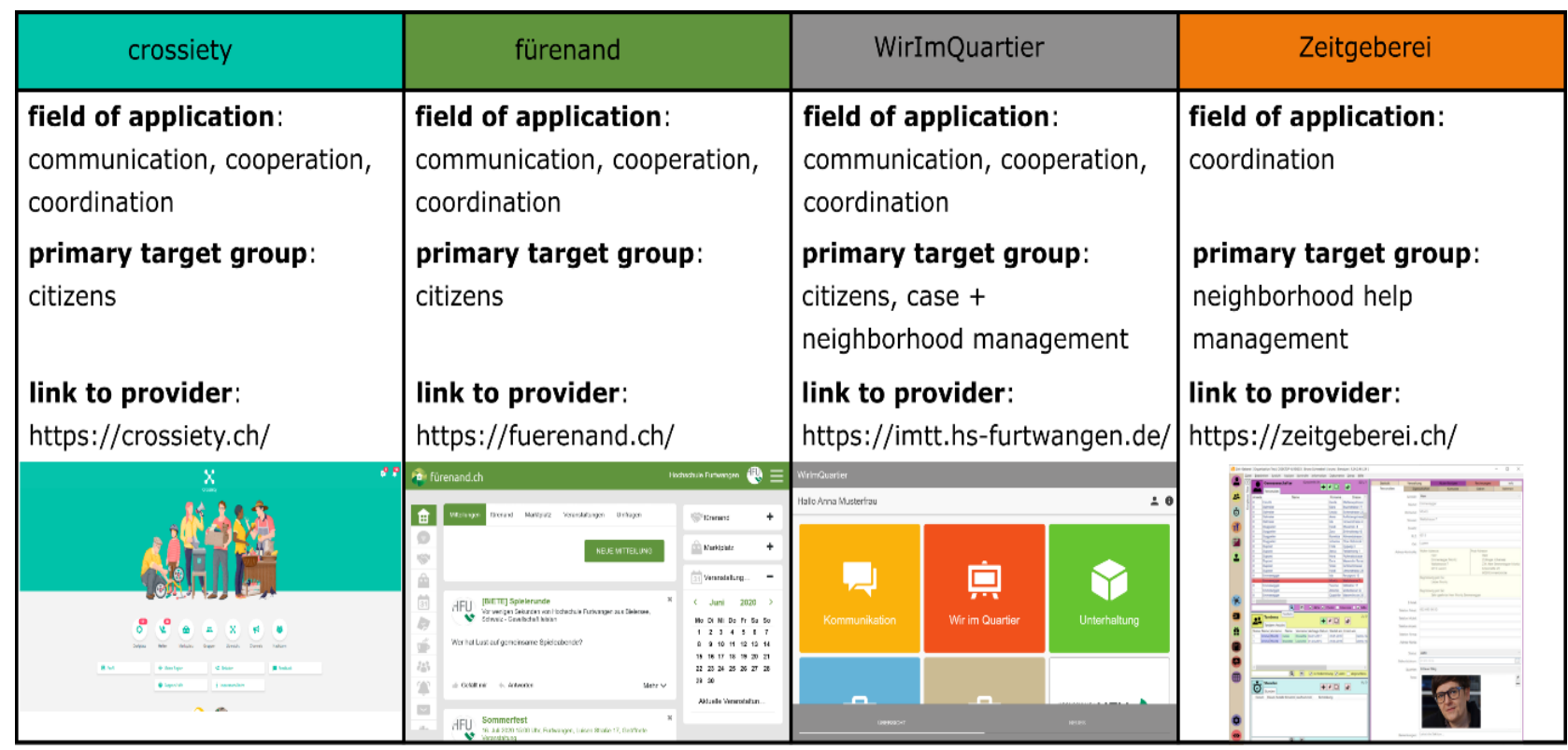

Figure 1: The four top platforms considered for neighborhood development in this study

The challenge consisted in reconciling requirements put forward by various user groups. As is the case in other social media applications, a balance between ease of use and openness vs. data protection had to be found. Most neighborhood platforms require users to register with their full name, age, and a real profile picture to prevent fake news and hateful content. Some of the neighborhoods voiced the need to moderate content on the platform in addition to the measures taken by the providers. For this purpose, they decided to regularly check user content. However, the fear of inappropriate content slipping through was not corroborated by data analysis.

Although all providers claimed that their platforms were easy to use and had intuitive and selfexplanatory user interfaces, a certain affinity for and openness to technology use proved to be a prerequisite for using the digital solutions effectively and efficiently. Additionally, hardware such as mobile devices with touch functions or keyboards require fine motor skills, which may restrict access for certain user groups. Platform technology also sometimes was not compatible with older devices. In several neighborhoods, therefore, discussions were held about how the target group could be equipped with suitable devices because senior citizens were often reluctant to purchase new equipment. 
"My mother at 88 is exactly THE target audience. She would love to knit or go for a walk with someone. But she won't be able to use this APP: firstly for fine motor reasons. She would never be able to write anything. (...) My mother can't "swipe" either and even if it looks bigger, she won't be able to handle the keyboard." (e-mail correspondence, citizen, neighborhood 10, Switzerland, 2018)

Whilst the platforms in Figure 1 fulfilled most requirements, there was room for improvement in user friendliness, ease of use, and accessibility for people with disabilities. Some of the providers have taken end-user feedback into consideration and are incorporating it into their platforms.

\section{Raising Awareness and Marketing}

Different awareness-raising strategies and marketing measures were used to propagate the new neighborhood platforms. These included posters, presentations at events, flyers, articles in neighborhood newsletters, invitations to open houses of the facilities, online advertising, and private communications to residents. Word-of-mouth and personal interaction proved to be the most effective measures. A key role was played by the person responsible for the platform. Their ability to communicate the added value of digital support in a convincing and tangible way was one of the most important success factors for a neighborhood platform.

\section{"(...) is now "supporter" and actively goes to help others with questions and problems" (interview protocol, municipal project responsible, neighborhood 4+5+6, Switzerland, 2020)}

Municipalities or sponsors usually financed the expenses incurred by these activities, not the software providers. The providers' primary responsibility was to guarantee operational safety and platform maintenance. People wanted to be assured that the platform was a long-term enterprise and continuously updated. Thus, start-ups were generally met with skepticism. At the same time, people had reservations and privacy concerns with regard to large commercial providers. An important issue during the onboarding phase was the often-voiced desire for the provider to be willing to accompany the organizers in the process. Contact details such as an email address or a telephone number where the platform provider could be reached were expected.

\section{Generating Content and Traffic}

Interesting content is essential to attracting citizens to the platform and motivating them to participate long-term. In cases where the projects were initiated by volunteers, this proved to be a major challenge, since the ongoing task of providing content was time-consuming and at times burdensome. In most neighborhoods, users demonstrated passive "consumer behavior" with very few people contributing their own posts. To counteract this problem, organizers often decided to generate content before officially introducing the neighborhood platform, thus making it more attractive and motivating users to add their own posts. 
In some communities, COVID-19 lockdowns led to an increase in traffic. The number of registrations rose dramatically, and many participants volunteered to help. Existing platforms often were considered an important source of information. Authorities could use them to provide updates in real time and were able to respond very quickly to questions from the citizens who therefore felt better informed than through the newspaper or other social media. Activities such as sewing masks were also organized via the neighborhood platform, and restaurants could publish their takeaway and delivery services. Unfortunately, some communities reported that the traffic rate decreased considerably after the first lockdown in spring 2020. The COVID-19 pandemic also caused delays, especially when the onboarding phase was still in progress. There was widespread uncertainly about how to deal with groups at risk, and offline activities had to be suspended until after the lockdown.

Training for both organizers and end-users proved to be a significant issue as well. In one neighborhood, two training sessions were offered in the town hall and one at a café for senior citizens. In the test phase, several training sessions were offered to crucial stakeholders to explain the technology and the ideas and rationale behind the platform. In one neighborhood, tandems were formed to match inexperienced with experienced technology users.

\section{Stakeholders and their Roles}

Throughout the accompanied neighborhoods, different actors were involved and participated in the projects in different ways and to varying degrees. They assumed roles in the projects based on their involvement, their activities, and their existing responsibilities.

\section{Involved Actors}

Eight main actors were involved in the various neighborhood projects: citizens, municipalities, associations, neighborhood assistance providers, local businesses, care service providers, technology providers, and scientific partners.

Citizens: Citizens networked on an individual basis and in organized forms. They were involved in a wide variety of activities, bringing in their own ideas. In many neighborhoods, operational groups were formed to organize themselves and the project activities bottom-up. Sometimes, subgroups were formed to optimize the technology implementation, such as technical groups, activity groups, sustainability groups, or facility groups. However, there was often a lack of committed citizens who were open to taking on responsibility. The citizens' activities included analyzing needs, specifying requirements, testing technology, planning projects, onboarding, marketing, and supporting other citizens with their technology usage.

Municipalities: The municipalities' activity varied between neighborhoods. Structural development of organized neighborhood assistance was in many cases especially promoted by local municipalities. Communities where the municipalities demonstrated willingness to council and support such projects seemed more successful, as there tended to be a clearer strategy, especially in terms of financial matters. Municipalities were actively involved in providing organizational and subject matter support, offering facilities, and holding official negotiations with technology providers. 
Associations: Different kinds of associations participated in the technology implementations, including sport clubs, church congregations, and self-help clubs. As they were firmly anchored in the communities, associations could reach out directly to citizens. Participating associations realized the benefits of digital technology for activities like expanding their current offers and reaching out to new target groups. For this, they happily provided resources such as association centers or cafés. Associations also provided financial support for the neighborhood projects.

Neighborhood Assistance Providers: Neighborhood assistance was organized through professional care service providers or in neighborhood help associations. Often, neighborhood help associations supported and coordinated the digitization projects. Neighborhoods where neighborhood assistance was professionally established benefited from the possibility of scaling up structures and services as needed, especially during the COVID-19 pandemic. The use of a mixture of old (e.g., phone) and new (e.g., matching tool or neighborhood platform) communication technologies enabled participation across generations.

Local Businesses: In some neighborhoods, local businesses actively participated in the development of the neighborhood projects and the establishment of the communities around them. The network allowed them to expand their offers on the platform, especially during the COVID-19 pandemic. However, the involvement of businesses was not always part of the project scopes.

Care Service Providers: Like local businesses, care service providers were optional players. If involved, they supported the project in their function as gatekeepers for reaching out to vulnerable groups, like seniors or disabled persons.

\section{"There is a need for gatekeepers to identify people who need support, even more so when it comes to vulnerable groups." (meeting protocol, care service provider, neighborhood 14, Switzerland, 2019)}

Technology Providers: Technology providers played a central role in the projects. As they had an interest in disseminating their offerings, they enthusiastically presented their concepts onsite, provided free test platforms for interested neighborhood groups, cooperated with local operating groups to adapt the platforms to local needs, and supported the introduction with marketing material. Some platform providers even made available a telephone contact or feedback functions. In addition, training events and workshops were held onsite with the neighborhood operational groups.

Scientific Partners: As this article is a product of scientific evaluations, the researchers, to a certain degree, influenced all surveyed neighborhoods. The researchers used different quantitative and qualitative methods and tools to measure, evaluate, and support the neighborhood projects. In several neighborhoods, the research cooperation went beyond activity evaluation. Their support in strategy development was highly valued by the neighborhoods. In three cases, the researchers originally had a dual role as consultants and technology providers. In the process of choosing a technology, however, the project groups decided on third-party technologies so that the researchers could leave the role of the provider. The researchers were 
also involved in networking with various stakeholders. In the initiating phase especially, they were involved in the conceptual work and the recruitment of project partners.

Roles

Appendix Table 1 presents a list of all identified roles, the associated stakeholders, and their tasks and competencies.

\section{Contradictory Facets}

The analysis revealed that the process of designing, selecting, and implementing digital interaction systems in neighborhood development is often characterized by conflicting goals and requirements, uncertainties, and complex interdependencies. These cannot be completely resolved and therefore require appropriate consideration during project management.

Interplay between online neighborhood work and physical interactions

While digital platforms are usually meant to supplement interactions in person, they depend on encounters and social interactions in the physical world as prerequisites for initiation, onboarding, and training. Service providers often act as gatekeepers to user groups. Sometimes, digital services are seen as a substitute rather than a supplement of existing structures. Even as analogous communication channels such as printed community news fade away, there is often still no strategy for social media presence and use.

\section{Role of strong existing neighborhood management structures}

While strong existing neighborhood management structures are usually seen as facilitators for the introduction of digital neighborhood services, they can also act as barriers. When networking and cooperation structures and neighborhood services are strong, less need is perceived for the introduction of a digital platform. In rural areas especially, a strong identification with the neighborhood and a high need for digital interaction meets missing digital infrastructure.

\section{Role of strategic planning in digitalization activities}

A clear vision and strategy are important to derive tangible objectives and to promote the commitment of institutional actors and multipliers. However, strategic planning takes time, and the dynamic nature of digital transformation requires agile management. In neighborhood development, top-down approaches can be perceived as control and discourage participation, while bottom-up discussions promote a team spirit and cohesion.

"Official strategies do not exist. Developing them would require resources that we do not have." (protocol maturity model, neighborhood manager, neighborhood 14, Switzerland, 2019) 


\section{Role of start-up funding for innovation activities}

While external funding is essential for planning, preparation, and implementation in most cases, long-term follow-up funding is crucial for a sustainable operation. The development of sustainable operation models is usually seen as a project goal that is not always accomplished. The availability of external resources in the initiation phase (e.g., researcher support or professional support from the municipality) can lead to dependencies. Thus, exit strategies are needed to support a sustainable operation after the innovation project ends. Innovation sometimes also seems to be its own goal, shaping an innovative image for the municipality but carrying the inherent risk of unsustainable developments.

\section{Municipality funded "club of the 6 municipalities" to find sustainable structures for future neighborhood development (project protocol, neighborhood 8, mayor, Germany, 2020)}

The value of individual vs. generic / self-managed vs. commercial solutions

In some neighborhoods, there are reservations about large commercial operators due to privacy concerns. Local neighborhood platforms are considered an alternative to "big social media." However, there are sustainability concerns about start-up companies or platforms provided by research projects. In some communities, participatory approaches lead to the development of individual software solutions. Their sustainability is questionable because their operation usually depends heavily on individual volunteers, but such local developments can lead to a tendency to avoid using other, outside solutions (not-invented-here syndrome).

"We don't want to make a media group rich, but we also don't want to drive a startup to the wall. We want to meet somewhere in between. The thing should be so sustainable that you don't have to say after 3 years, now that it's up and running, it's broken." (conversation protocol, gatekeeper, neighborhood 12+13, Germany, 2020)

\section{The methods of community management and onboarding}

To prevent hate speech and misuse, digital neighborhood platforms usually implement stronger access restrictions compared to general social media platforms: for instance, access only for people with checked identities and/or people living in the neighborhood. This may be a barrier to onboarding and community self-management. The inclusion of vulnerable and marginalized groups is seen as an important goal. However, a strong emphasis on additional measures to support inclusion can be perceived as stigmatizing or as exclusive towards nonmarginalized groups. 


\section{Discussion}

\section{Lessons Learned}

Based on the findings presented above, we can draw three major lessons learned from this study:

1. Digitization projects must fit into the overall strategy of the neighborhood development and be driven by a committed (group of) responsible(s)

In most cases, digitization projects should enable all local stakeholders to participate in strategy development, even though they might not be the future target users. This is stressed by Schelisch and Walter (2021) and aligns with Vogel et al.'s 2020 notion of digital networks as socio-technical artifacts that need to be embedded in local contexts. The introduction of digital tools is especially successful if it contributes to the achievement of general neighborhood development goals and is not an end in itself. In this case, it may lead to better intergenerational networking, livelier neighborhoods, improved life quality for residents, and a new sense of community. The initiation of a technology project is afflicted with a high demand of time, especially during the development of strategies and goals. Like Schneider and Göppert (2018), we emphasize that the presence of a committed and responsible person or a neighborhood manager can significantly empower the entire project.

\section{Choosing a technology is not a linear process and takes time}

Choosing a technology in some cases was an iterative process. In general, this process can be broken down into the following steps, as seen in Figure 2: first, clarify needs and objectives; second, compare offers (examine the strengths and weaknesses of the technologies; weigh, compare, and evaluate modules and functionalities; and consider individual vs. existing, proven solutions); third, invite and become familiar with the provider; fourth, test the technology with a selected group over a few weeks; fifth, decide for or against the technology. In case of uncertainty, return to the first step.

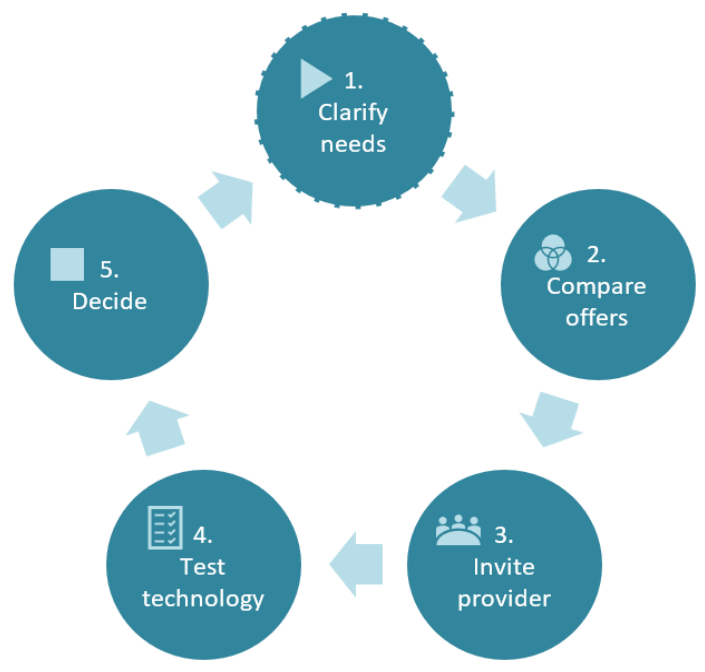

Figure 2: Steps of the technology selection phase 
Reasons for choosing or rejecting a technological solution included reliability, simplicity, adaptability, operational safety, and sustainability; the operator's support, including their perceived competence and availability; the cost of maintenance; the commitment of as many decisionmakers as possible; sufficient financial resources; and a solution that is as uncomplicated and easy to finance as possible. As Vogel et al. (2020) state, the combination of technological and societal factors cannot be evaluated with technological criteria alone.

A catalog of criteria, an objective overview of technology solutions, and concrete examples to illustrate and demonstrate the added value of the technology can be helpful in selecting the best fit. This is in line with the determinants of perceived usefulness laid out by Venkatesh and Bala (2008) for the Technology Acceptance Model, first developed by Davis et al. (1989).

Sufficient attention should be paid to the needs of the users because uncertainties in this regard make the choice of technology difficult. Along with privacy concerns, as seen in Masden et al. (2014), user competence and technology availability (e.g., of Internet and cell phones) should also be taken into account, as access to and proficiency in using technology can differ greatly among potential users (Vogel et al., 2019). Existing structures, critical analysis of the present situation, as well as clear visions and objectives for the future are usually prerequisites for technology use.

On a small scale, a test phase should be performed. One of the goals of a test phase is to become familiar with the technology and its functions - between two weeks tested by ten users to ten weeks tested by 20 users seemed to be sufficient. When the operating group or responsible person is able to answer all open questions, the system can be scaled up to the whole neighborhood. Not only did the neighborhoods benefit from the test phases, but also the technology providers, because users reported any difficulties, for example, in the registration process, and desires for improvements.

For the technology selection, sufficient time must be allowed and decisions not made hastily.

\section{The benefit comes through the use}

Gatekeepers are essential for identifying potential users, especially if the target group consists of vulnerable persons in need of support (Schelisch \& Walter, 2021). These gatekeepers must be close to the neighborhood and open to personally approach or being approached by potential users. Gatekeepers can be motivated volunteers, professionals, and local institutions. Convincing local businesses (e.g., a district store or bakery) to use a neighborhood platform is not always easy. The attractiveness of the platform rises with the number of platform users. In particular, with the common phenomenon of "consumerism" among civil platform users, a high number of local businesses posting their offerings increases attractivity for civil users, especially in the beginning. Low traffic and a lack of exciting content can lead in the worst case to a decline in users. To prevent a vicious circle of non-activity and hence user decrease, active community members in charge of the project who regularly look after the community and encourage traffic are necessary. 
Reluctance to seek assistance as described by Vogel et al. (2019), existing mostly among senior users, was also observed in this study, especially in the neighborhood communication platforms. In neighborhoods that were actively managed by well-organized neighborhood assistance initiatives, this effect seemed to be mitigated, as the matching tool did not get visible for the senior (calling the neighborhood assistance) and the care seeker's anonymity was preserved.

\section{Limitations}

The contribution of this study should be viewed in light of the following limitations. First, the selection of the neighborhoods was an attempt to cover the diversity of the Lake Constance region. However, since not every neighborhood is open for scientific support or sees a need for change at all, it can be assumed that some individual aspects of (digital) neighborhood work could not find their way into this study. Second, in this study, we focused on summarizing experiences and recommendations for action that should enable a broad, cross-national transfer and discussion. We constrained the scope of our analysis to the implementation of ICT for neighborhood development, although other technologies may be useful or applicable in this context. Third, since the researchers were partially personally involved in the neighborhood projects, also the call in of an external research collaborator, cannot fully eliminate the risk of subjectivity and bias.

\section{Conclusion}

This article presents the lessons learned from a cross-national project accompanying 14 neighborhoods from Germany, Austria, and Switzerland on their way to digitally supported neighborhood work. The general conditions, the implementation process, the technology itself, and the various stakeholders all played a significant role on the path to a digitally supported neighborhood. Especially, neighborhood managers played a key role for the success of the projects by e.g. communicating the added value of digital support in a convincing and tangible way. Moreover, the analysis has shown that given the diversity of the neighborhoods involved there is no 'gold standard' but that the key success factors may take on different meanings in different neighborhoods. Among these are the interplay between online neighborhood work and physical interactions, the role of strong existing neighborhood management structures, the role of strategic planning in digitalization activities, the role of start-up funding for innovation activities, the value of individual vs. generic and self-managed vs. commercial solutions, and the methods of community management and onboarding. The projects provide valuable experiences related to technology usage and the multitude of challenges associated with digital neighborhood work. The COVID-19 pandemic can be regarded as one of these challenges, but also as an enabler for change.

Given the great challenges that usually have to be faced in digitally supported neighborhood projects and the many pitfalls one may encounter on this path, guidelines or models, like the developed maturity model by Renyi et al. (2020), might facilitate the exchange of best practice and experience between projects. The researchers hope this article will contribute to this exchange and will help the scientific community and practitioners alike to realize digitally supported neighborhood projects. 


\section{References}

Bäuerle, D., Scherzer, U. (2009). Zukunft Quartier - Lebensräume zum Älterwerden - Themenheft 1: Hilfe-Mix - Ältere Menschen in Balance zwischen Selbsthilfe und (professioneller) Unterstützung. Netzwerk: Soziales neu gestalten (SONG). Retrieved from http://www.netzwerk-song.de/fileadmin/user upload/Themenheft1.pdf

Davis, F. D., Bagozzi, R. P., \& Warshaw, P. R. (1989). User acceptance of computer technology: A comparison of two theoretical models. Management Science, 35(8), 982-1003.

Deutscher Bundestag (2016): Siebter Bericht zur Lage der älteren Generation in der BRD: Sorge und Mitverantwortung in der Kommune - Aufbau und Sicherung zukunftsfähiger Gemeinschaften (BT-Drs. 18/10210). Köln: Bundesanzeiger Verlagsges. GmbH Retrieved from https://www.siebter-altenbericht.de

Internationale Bodensee Hochschule (2020). Technik im Quartier. https://www.bodenseehochschule.org/labs/ibh-labs/ibh-lab-aal/technik-im-quartier/ last accessed 13.03.2021

Klie, T. (2016). “On the Way to a Caring Community?," In Wegleitner, K. Heimerl, K., Kellehear, A (eds.) Compassionate Communities: Case Studies from Britain and Europe, Routledge (pp. 198-209). Retrieved from https://doi.org/10.4324/9781315735801-14

Kuckartz, U. (2014). Three basic methods of qualitative text analysis. In Kuckartz, U. Qualitative text analysis: A guide to methods, practice \& using software. SAGE Publications. (pp. 65120) Retrieved from https://doi.org/10.4135/9781446288719

Kuckartz, U. (2016). Qualitative Inhaltsanalyse. Methoden, Praxis, Computerunterstützung. 3. Überarbeitete Auflage, (Grundlagen.), Weinheim Basel: Beltz Verlag. Retrieved from http://www.beltz.de/de/nc/verlagsgruppe-beltz/gesamtprogramm.html?isbn=978-3$\underline{7799-3344-1}$

Masden, C. A., Grevet, C., Grinter, R. E., Gilbert, E., \& Edwards, W. K. (2014). Tensions in scalingup community social media: a multi-neighborhood study of nextdoor. In Proceedings of the SIGCHI conference on Human factors in computing system. Association for Computing Machinery. (pp. 3239-3248) Retrieved from https://doi.org/10.1145/2556288.2557319

Meyer, S. (2016). Technische Unterstützung im Alter: Was ist möglich, was ist sinnvoll? In Block, J. Hagen, C. \& Berner, F. (eds) Expertisen zum Siebten Altenbericht der Bundesregierung. Berlin: Deutsches Zentrum für Altersfragen.

Michell-Auli, P. \& Kremer-Preiß, U. (2013). Quartiersentwicklung. KDA-Ansatz und kommunale Praxis. Medhochzwei Verlag.

Renyi, M., Hegedüs, A., Maier, E., Teuteberg, F., \& Kunze, C. (2020). Toward Sustainable ICTSupported Neighborhood Development-A Maturity Model. Sustainability, 12(22), 9319. Retrieved from https://doi.org/10.3390/su12229319 
Röll, N., Stephan, R, Stork, W., Kunze, C., \& König, P. (2016). Beratung zu technischen Hilfen im Alter - Erfahrungen aus dem Projekt "Wegweiser: Besser Leben im Alter durch Technik", Zukunft Lebensräume. VDE Verlag.

Schelisch, L., \& Walter, R. (2021). Digital Networking in Home-Based Support of Older Adults in Rural Areas: Requirements for Digital Solutions. Sustainability, 13(4), 1946. Retrieved from https://doi.org/10.3390/su13041946

Schreiber, F., \& Göppert, H. (2018). "Wandel von Nachbarschaft in Zeiten Digitaler Vernetzung. Explorationsstudie Zur Wirkung Digitaler Medien Mit Lokalem Bezug Auf Sozialen Zusammenhalt Und Lokale Teilhabe in Quartieren.," adelphi, Berlin.

Steffen, G., \& Otto, U. (2017). Unterschiedliche Stadtquartiere und Quartierstypen - wie eignen sie sich für heutiges und künftiges Älterwerden? In Sinning, H., Steffen, G., Otto, U. et al (eds.), Altersgerecht wohnen und leben im Quartier. Trends, Anforderungen und Modelle für Stadtplanung und Wohnungswirtschaft. IRB Fraunhofer, pp. 53-70

Venkatesh, V., \& Bala, H. (2008). Technology acceptance model 3 and a research agenda on interventions. Decision Sciences, 39(2), 273-315.

Vogel, P., Jurcevic, N., \& Meyer-Blankart, C. (2019). Healthy, Active and Connected: Towards Designing an Age-Friendly Digital Neighborhood Platform. In Johannesson, P., Agerfalk, P., Helms, R. (eds.) Twenty-Seventh European Conference on Information Systems (ECIS2019), Stockholm-Uppsala, Sweden. AIS digital library. Retrieved from https://aisel.aisnet.org/ecis2019 rip/5/

Vogel, P., Grotherr, C., Kurtz, C., \& Böhmann, T. (2020). Conceptualizing Design Parameters of Online Neighborhood Social Networks. In Gronau, N, Heine, M., Krasnova, H., Poustcchi, K. (eds.) Entwicklungen, Chancen und Herausforderungen der Digitalisierung: Proceedings der 15. Internationalen Tagung Wirtschaftsinformatik. GITO Verlag. (pp. 1593-1608)

WHO. World Health Organisation (2007). Global age-friendly cities. A guide (English Version). WHO. Retrieved from www.who.int/ageing/age friendly cities guide/en/

Zeidler, J., Braun, S. (2012) Sekundärdatenanalysen. In Schöffski, O. \& Graf v.d. Schulenburg, J.M.: Gesundheitsökonomische Evaluationen. Springer-Verlag. Berlin Heidelberg. Retrieved from https://doi.org/10.1007/978-3-642-21700-5 10 
Appendix

Appendix Table 1: List of roles and associated neighborhood stakeholders including their tasks and competencies.

\begin{tabular}{|c|c|c|}
\hline Roles & Description & Tasks and Competencies of the Stakeholders \\
\hline $\begin{array}{l}\text { Operational } \\
\text { group / } \\
\text { Volunteer } \\
\text { group }\end{array}$ & $\begin{array}{l}\text { Engaged local } \\
\text { community } \\
\text { (stakeholders); } \\
\text { participated in all } \\
\text { stages; early } \\
\text { involvement } \\
\text { required }\end{array}$ & $\begin{array}{l}\text { Citizens: Voluntary members from community who self- } \\
\text { organized, formed working groups, and generated content } \\
\text { and traffic on the platforms } \\
\text { Associations: Established, coordinated, and/or provided } \\
\text { content and services on platform } \\
\text { Neighborhood assistance providers: Supported working } \\
\text { group } \\
\text { Care service providers: Supported working group }\end{array}$ \\
\hline Initiator & $\begin{array}{l}\text { Active or passive } \\
\text { involvement; } \\
\text { developed and } \\
\text { promoted project } \\
\text { / initiatives / } \\
\text { concepts / } \\
\text { services }\end{array}$ & $\begin{array}{l}\text { Citizens: Launched initiatives, developed concept, } \\
\text { supported evaluation and implementation of project, and } \\
\text { generated initial traffic and content on platform } \\
\text { Municipality: Promoted and supported projects and } \\
\text { operational groups or neighborhood associations and } \\
\text { defined strategy } \\
\text { Associations: Promoted project } \\
\text { Neighborhood assistance providers: Launched initiatives } \\
\text { and developed concept } \\
\text { Technology provider: Disseminated technology (platform) } \\
\text { Scientific partners: Recruited project partners }\end{array}$ \\
\hline $\begin{array}{l}\text { Sponsor / } \\
\text { Investor }\end{array}$ & $\begin{array}{l}\text { Enabled } \\
\text { neighborhood } \\
\text { projects }\end{array}$ & $\begin{array}{l}\text { Municipality: Provided financial support, facilities, } \\
\text { infrastructure, and personnel; determined requirements } \\
\text { for the project } \\
\text { Associations: Provided financial support, facilities, } \\
\text { infrastructure, and personnel; determined requirements } \\
\text { for the project }\end{array}$ \\
\hline Management & $\begin{array}{l}\text { Managed } \\
\text { operations and } \\
\text { finance }\end{array}$ & $\begin{array}{l}\text { Municipality: Managed during operation phase, financially } \\
\text { assessed project, and negotiated with operators of digital } \\
\text { neighborhood platforms } \\
\text { Neighborhood assistance providers: Organized and } \\
\text { coordinated operational groups } \\
\text { Scientific partners: Networked with various stakeholders }\end{array}$ \\
\hline $\begin{array}{l}\text { Technology } \\
\text { support }\end{array}$ & $\begin{array}{l}\text { Supported in } \\
\text { technical } \\
\text { problems and } \\
\text { questions; } \\
\text { sometimes part of } \\
\text { operational group }\end{array}$ & $\begin{array}{l}\text { Citizens: Supported introduction of technology } \\
\text { Technology provider: Provided test bed and technical } \\
\text { support and acted as point of contact for technical / } \\
\text { system issues } \\
\text { Scientific partners: Provided technical support during } \\
\text { project }\end{array}$ \\
\hline
\end{tabular}




\begin{tabular}{|c|c|c|}
\hline $\begin{array}{l}\text { Platform } \\
\text { developer }\end{array}$ & $\begin{array}{l}\text { Developed and } \\
\text { provided } \\
\text { technical } \\
\text { infrastructure } \\
\text { (platform) }\end{array}$ & $\begin{array}{l}\text { Technology provider: Provided technical infrastructure } \\
\text { (platform) and exchanged information with stakeholders / } \\
\text { groups } \\
\text { Scientific Partners: sometimes also acted as technology } \\
\text { provider }\end{array}$ \\
\hline Gatekeeper & $\begin{array}{l}\text { Identified } \\
\text { (vulnerable) } \\
\text { groups and } \\
\text { integrated } \\
\text { particular groups } \\
\text { into community }\end{array}$ & $\begin{array}{l}\text { Citizens: Offered support for relatives and friends } \\
\text { Care service providers: Identified particular (vulnerable) } \\
\text { groups and provided assistance and information to target } \\
\text { groups }\end{array}$ \\
\hline Consultant & $\begin{array}{l}\text { Externally } \\
\text { supported project } \\
\text { team and } \\
\text { accompanied } \\
\text { technology } \\
\text { introduction and } \\
\text { dissemination }\end{array}$ & $\begin{array}{l}\text { Technology provider: Supported on various levels and in } \\
\text { various phases, provided best-practice examples, and } \\
\text { organized and conducted workshops } \\
\text { Scientific partners: Provided best-practice examples, } \\
\text { informed project group on experiences from similar } \\
\text { projects and research, executed user-requirement surveys, } \\
\text { assisted in conception and implementation of project }\end{array}$ \\
\hline User & $\begin{array}{l}\text { Used platform } \\
\text { and created value } \\
\text { of platform for } \\
\text { target groups }\end{array}$ & $\begin{array}{l}\text { Citizens: Used platform, consumed content, generated } \\
\text { content and traffic, and promoted platform within } \\
\text { neighborhood } \\
\text { Associations: Coordinated and/or provided content and } \\
\text { services on platform } \\
\text { Local businesses: Provided goods and services on platform } \\
\text { Neighborhood assistance providers: Provided (and } \\
\text { integrated) services on platform } \\
\text { Care service providers: Provided (and integrated) services } \\
\text { on platform }\end{array}$ \\
\hline
\end{tabular}

